ISSN 0103-9954

\title{
AVALIAÇÃO DA ARBORIZAÇÃO URBANA PELOS RESIDENTES - ESTUDO DE CASO EM MÁL. CÂNDIDO RONDON, PARANÁ
}

\section{EVALUATION OF THE URBAN ARBORIZATION BY THE RESIDENTS - A CASE STUDY OF MAL. CÂNDIDO RONDON, PARANÁ}

\author{
Ubirajara Contro Malavasi $^{1} \quad$ Marlene de Matos Malavasi ${ }^{1}$
}

\begin{abstract}
RESUMO
Este estudo objetivou quantificar a percepção da arborização urbana da cidade de Mal. Cândido Rondon, Paraná, pelos munícipes residentes. Os dados foram obtidos por meio da aplicação de um questionário a trinta residentes localizados em 53 pontos de amostragem da área urbana do município perfazendo um total de 1.590 entrevistas. Os resultados indicaram que, para $56 \%$ da população urbana, a cidade de Mal. Cândido Rondon, assim como a rua de residência do munícipe possuem alguma arborização. Dos entrevistados, $92 \%$ percebem alguma vantagem da presença da arborização sendo que os benefícios relacionados com o conforto térmico foram os mais lembrados. $75 \%$ dos entrevistados declararam sua colaboração na manutenção da arborização urbana. A valoração da arborização urbana pelos munícipes rondonenses refletiu-se no fato de que $91 \%$ dos entrevistados se declararem propensos a contribuir anualmente com valores entre $\mathrm{R} \$ 1,00$ e $\mathrm{R} \$ 5,00$ para a sua manutenção.
\end{abstract}

Palavras-chave: opinião pública, valoração, manutenção, participação comunitária.

\begin{abstract}
The study has had as its objective to evaluate resident perception and valorization of urban trees by residents of Mal. Cândido Rondon, Paraná. Date were collected from 1590 interviews, being selected 53 sample points with 30 residents in each point. Fifty six percent of the county urban residents classified the city, and their street of residency as reasonably forested. Meanwhile, $92 \%$ indicated perceiving some advantages by the presence of urban trees. The most frequent advantages were related to environment amelioration. Ninety one percent of the responses indicated that residents would be willing to contribute with $\mathrm{R} \$ 1,00$ to $\mathrm{R} \$ 5,00$ annually in order to maintain urban trees.
\end{abstract}

Key words: public opinion, valorization, maintenance, social participation.

\section{INTRODUÇÃO}

A arborização das cidades, provavelmente, surgiu com o intuito de garantir o vínculo atávico do homem com o "natural." A literatura é pródiga na lista de benefícios decorrentes da arborização urbana. Os benefícios mais citados incluem a redução de ruídos, as modificações do microclima, a

1. Professor do Centro de Ciências Agrárias, UNIOESTE, Rua Pernambuco, 1777, CEP 85960-000, Mal. Cândido Rondon (PR).umala@unioeste.br 
alteração do campo visual, a melhoria do hábitat da fauna silvestre, assim como a recreação e lazer urbanos (SOUZA, 1995). As propriedades inerentes ao bem-estar do homem citadino estão, portanto, vinculadas ao componente vegetal que faz parte dos aglomerados urbanos. Plantar árvores nas cidades significa assim atender a dupla natureza humana: a biológica e a cultural. No entanto, a percepção da arborização urbana pela população humana tem sido relegada a um plano secundário pelos administradores e técnicos responsáveis.

Os parâmetros utilizados para a avaliação da arborização urbana baseiam-se geralmente na observação e mensuração de variáveis biológicas embora tenha sido já admitido que fatores sentimentais, psicológicos e estéticos são importantes (OLIVEIRA, 1996). Por outro lado, publicações sobre arborização urbana, como por exemplo aquele da CEMIG (1996), sempre colocaram a perfeita interação homem-árvore como fator modulador do sucesso nas diversas fases da arborização urbana.

MILANO (1984) alertou que a falta de participação comunitária nos programas de arborização gera sérios prejuízos. Desde aquele alerta, o "vandalismo" tornou-se uma das mais conspícuas formas de interação entre o homem urbano e a arborização. A educação dos munícipes com relação aos efeitos benéficos da arborização é uma forma de reduzir os efeitos deletérios do vandalismo. Portanto, necessário se faz acrescentar aos métodos empregados em planejamento e manejo da arborização uma avaliação das percepções dos seus usuários finais (MALAVASI, 1994).

A arborização da zona urbana de Mal. Cândido Rondon, situada na microrregião oeste do estado do Paraná, constitui-se de um total de, aproximadamente, 15.483 árvores conforme inventário realizado pela Prefeitura Municipal. As espécies mais freqüentes são Lagestroemia indica L., Jacaranda mimosifolia D.Don, Delonix regia Raf., Caesalpinia pelthophoroides Benth., Ligustrum lucidum L., Mangifera indica L., Cássia fistula L., Magnólia grandiflora L., Bauhinia candicans Benthon e Tipuana tipu (Benth) Kunth.

Este estudo teve como objetivo quantificar a percepção da arborização na zona urbana da cidade de Mal. Cândido Rondon pela ótica de seus residentes urbanos.

\section{MATERIAL E MÉTODOS}

A cidade de Mal. Cândido Rondon possui as coordenadas de $24^{\circ} 33^{\prime} 40^{\prime \prime} \mathrm{S}$ e $54^{\circ} 04^{\prime} 00^{\prime \prime} \mathrm{W}$ e apresenta um clima subtropical úmido mesotérmico com verões quentes e uma temperatura média superior a $22^{\circ} \mathrm{C}$, invernos com temperatura média inferior a $18^{\circ} \mathrm{C}$ e geadas pouco freqüentes, e sem estação seca definida. A área total do município é de $846 \mathrm{~km}^{2}$ a uma altitude média de $40 \mathrm{~m}$. A população urbana do município contabiliza 22.802 habitantes. A população é predominantemente de origem européia predominando a germânica.

Um questionário com dez perguntas foi utilizado para a obtenção dos dados, sendo aplicado mediante uma amostragem sistemática. A designação dos pontos de amostragem foi sistematizada no sentido leste-oeste dentro dos limites da zona urbana reconhecida pela prefeitura que totaliza 14,4 $\mathrm{km}^{2}$, utilizando um mapa na escala de $1: 7.500$. Todas as décimas interseções entre ruas 
constituíram-se em pontos de amostragem, totalizando 53 pontos. Em cada ponto de amostragem, foram aplicados trinta questionários aos residentes mais próximos da interseção. Foram entrevistados residentes de ambos os lados das ruas e os questionários foram aplicados somente a um residente por domicilio. O número total de entrevistados foi de 1.590 pessoas. Os dados percentuais obtidos foram transformados para arco seno da raiz quadrada e analisados utilizando o programa STATGRAPH.

\section{RESULTADOS E DISCUSSÃO}

Os entrevistados totalizaram $6,97 \%$ da população urbana rondonense. A discriminação dos entrevistados por gênero revelou que $59 \%$ dos participantes eram do sexo masculino enquanto $41 \%$ eram do sexo feminino. A escolaridade dos participantes mostrou que $11,2 \%$ possuíam o ensino fundamental completo, $26,6 \%$ possuíam o ensino intermediário completo enquanto $7,7 \%$ tinham completado o ensino superior. As percentagens de 26,6, 21,8 e 6,1\% foram encontradas para os entrevistados que não completaram o ciclo fundamental, intermediário e superior, respectivamente. Esses valores mostram que 45,5\% dos entrevistados já concluíram pelo menos um ciclo da educação formal. Com relação às atividades dos entrevistados, as respostas apontaram que a maior freqüência foi para a atividade DOMÉSTICA com 30\%, seguida da atividade AGRÍCOLA com 19\% e das atividades PROFISSIONAL LIBERAL/AUTÔNOMO e ESTUDANTE com $16 \%$ cada uma, respectivamente.

Quando instigados a atribuir uma classificação subjetiva a arborização da cidade de Mal. Cândido Rondon, utilizando as classes MUITO, RAZOÁVEL ou POUCO arborizada, os entrevistados escolheram a classe RAZOAVELMENTE ARBORIZADA (RA) em 56\% das respostas enquanto que as classes MUITO ARBORIZADA (MA) e POUCO ARBORIZADA (PA) foram anotadas em 37 e $7 \%$ das respostas, respectivamente. Embora subjetivas e sujeitas à influência de comparações baseadas na maior ou menor vivência do entrevistado, as classes utilizadas explicitaram a comparação da arborização local comparativamente a outras cidades. Quando solicitados a utilizar a mesma classificação em relação à arborização da rua de residência do entrevistado houve similaridade nas respostas obtidas. Nesse caso, a comparação implícita no questionamento foi entre a rua de residência do entrevistado e a cidade como um todo. As classificações (RA), (MA) e (PA) apresentaram freqüências de 54, 26 e $20 \%$ das respostas, respectivamente. A comparação entre as classificações (RA) atribuída à cidade como um todo e à rua de residência dos entrevistados não resultou em valores estatisticamente diferentes entre si $(\mathrm{P}>0,05)$. No entanto, as comparações entre as classificações (MA) e (PA) mostraram-se estatisticamente diferentes. Esses resultados refletem diferenças temporais no processo de urbanização e, conseqüentemente, na arborização da cidade onde as ruas mais "antigas" possuem uma arborização conspícua e de maior porte do que as ruas recentemente urbanizadas.

A questão da percepção de alguma vantagem ou desvantagem da arborização urbana rondonense foi abordada por meio de resposta exclusiva. A maioria dos entrevistados (92\%) apontou alguma vantagem da arborização urbana enquanto apenas $8 \%$ responderam que as desvantagens prevalecem sobre as vantagens. Dentre as vantagens aludidas pelos entrevistados o SOMBREAMENTO com $65 \%$ e a REDUÇÃO DO CALOR com $23 \%$ foram as mais freqüentes, 
seguidas pela PRESENÇA DE FLORES e pela REDUÇÃO DOS RUÍDOS com 4\% cada. Por outro lado, as desvantagens mais freqüentemente citadas foram a SUJEIRA DAS RUAS E CALÇADAS com $56 \%$ e a SUJEIRA PROVOCADA POR PÁSSAROS com 14\%, seguidas pela REDUÇÃO NA ILUMINAÇÃO PÚBLICA e PROBLEMAS COM A REDE ELÉTRICA ambas com $8 \%$ cada. A importância da arborização urbana para os munícipes varia de cidade para cidade e seus fatores determinantes são tanto culturais como climáticos (DIAS, 1996). A interpretação dos resultados aponta para que as vantagens mais freqüientes estarem diretamente relacionadas com o conforto térmico dos munícipes da cidade de Mal. Cândido Rondon por conta do clima quente e úmido da região enquanto as desvantagens relacionam-se com o orgulho citadino de uma cidade "limpa".

Quando perguntados sobre a quem devem ser encaminhadas as reclamações referentes à arborização urbana, 73\% dos entrevistados elegeram a PREFEITURA seguida da companhia de eletricidade COPEL com 14\% das respostas, enquanto apenas $11 \%$ declararam não saber a quem reclamar. Essas respostas estão em conformidade com a constatação de que a arborização urbana consiste de um bem público e portanto sobre os ditames da administração municipal. As prefeituras municipais devem executar e manter a arborização urbana, pois a competência para tal reside nos planos diretores e leis do uso do solo dos municípios ou regiões metropolitanas os quais devem observar os princípios e limites previstos no art. $2^{\circ}$, parágrafo único do Código Florestal que foi acrescentado pela lei 7.803/89 (SILVA, 1995).

O relacionamento entre a população residente e a arborização urbana da cidade de Mal. Cândido Rondon foi caracterizado mediante a pergunta de como os munícipes colaboram com a arborização urbana. Aos entrevistados, $73 \%$ declararam que colaboram de alguma maneira com a arborização municipal. As maneiras mais freqüentemente citadas pelos entrevistados foram PLANTANDO ÁRVORES, NÃO DANIFICANDO, e NÃO MALTRATANDO com 25, 24 e $20 \%$ das respostas, respectivamente. Esses dados revelam o posicionamento participativo dos munícipes entrevistados. No entanto, o adensamento da arborização urbana, revelado pela disposição do plantio voluntário de árvores, pode ser prejudicial à futura manutenção da arborização especialmente se a prefeitura não for notificada ou se não houver inventário freqüente da arborização. As outras duas maneiras de colaboração mencionadas são benéficas e demonstram o exercício da cidadania rondonense mormente em respeito ao bem público.

Quando questionados sobre a possibilidade de contribuir financeiramente para a manutenção da arborização urbana, 59\% dos questionados declararam-se favoráveis. Dentre aqueles que aceitaram a possibilidade de aporte financeiro o valor anual de $\mathrm{R} \$ 1,00$ (hum real) por residente foi o valor mais citado, 53\%; enquanto o valor entre $\mathrm{R} \$ 1,00$ (hum real) e $\mathrm{R} \$ 5,00$ (cinco reais) recebeu $38 \%$ das respostas. Esses resultados são semelhantes aos de LORENZO et al. (2000) no subúrbio de New Orleans (Estados Unidos da América) os quais concluíram que 88\% dos residentes entrevistados nominaram de BOM e de EXCELENTE aos programas de proteção e manutenção da arborização local e que ainda contribuiriam com valores de até US\$ 12 (doze dólares) anuais para a continuação daqueles programas. A valoração dos recursos naturais e em especial aqueles cênicos e de benefícios indiretos reveste-se de inúmeras dificuldades metodológicas. MOLL e YOUNG (1992) estimaram que, em média, uma árvore na área urbana de uma cidade localizada em área de clima 
temperado fornece "benefícios" ambientais anuais no valor de US\$ 273,00 (duzentos e setenta e três dólares); os autores levaram em consideração o efeito de amenização da temperatura no verão e inverno assim como a redução na concentração de dióxido de carbono e partículas suspensas no ar.

\section{CONCLUSÃO}

A falta da participação comunitária e da conscientização da importância da arborização urbana relacionam-se freqüentemente com os fracassos dos plantios em área urbanas. Os resultados obtidos junto à população urbana com o presente estudo indicam um apreço e reconhecimento generalizado da arborização urbana na cidade de Mal.Cândido Rondon, Paraná.

Para um eficiente planejamento e manutenção da arborização urbana necessário se faz considerar a percepção da população urbana . A disposição de colaborar deve ser canalizada pela autoridade municipal. A manifestação de aporte financeiro para a arborização por uma fração considerável da população traduz em valores monetários o sentimento de cidadania dos residentes. Nas condições deste estudo e da renda per capita local os resultados foram animadores com relação a uma futura e necessária reposição das árvores no meio urbano de Mal. Cândido Rondon.

\section{REFERÊNCIAS BIBLIOGRÁFICAS}

CEMIG. Manual de arborização. Belo Horizonte, MG. 1996. 40 p.

DIAS, R. A importância da arborização urbana. In: SEMINÁRIO DE ARBORIZAÇÃO URBANA NO RIO DE JANEIRO, 1., 1996, Rio de Janeiro. Anais ... Rio de Janeiro: UFRJ, 1996. p. 29 - 33.

LORENZO, A. B., BLANCHE, C. A., QI, Y. et al. Assessing residents' willingness to pay to preserve the community urban forest: a small-city case study. Journal of Arboriculture, v. 26, n. 6, p. 319-334, 2000.

MALAVASI, U.C. Florestas urbanas: elo de Ligação entre o Homo sapiens urbanus e o Meio Ambiente. Floresta e Ambiente, Rio de Janeiro, v. 1, n. 1, p. 58-59, 1994.

MILANO, M.S. Avaliação e análise da arborização de ruas de Curitiba-PR. 1984. 130p. Dissertação (Mestrado em Engenharia Florestal), Setor de Ciências Agrárias, Universidade Federal do Paraná, Curitiba.

MOLL, G.; YOUNG, S. Growing greener cities: a tree-planting book. Los Angeles: Living Planet Press. 1992. $126 \mathrm{p}$.

OLIVEIRA, R.F. de. De urbis arboreto: o espaço primitivo interpretado. In SEMINÁRIO DE ARBORIZAÇÃO URBANA NO RIO DE JANEIRO, 1., 1996, Rio de Janeiro. Anais ... Rio de Janeiro: UFRJ, 1996. p 33 - 44.

SILVA, J.A. da. Direito ambiental constitucional. 2. ed. São Paulo: Malheiros, 1995. 243 p.

SOUZA, M. A. de I.B. Curso sobre arborização urbana. Belo Horizonte: CEMIG/SBAU/IEF/AMIFLOR, 1995. $33 \mathrm{p}$. 